\title{
Reprocessability of molybdenum and magnesia based inert matrix fuels
}

Elena L. Ebert, Andrey Bukaemskiy, Fabian Sadowski, Steve Lange, Andreas Wilden, Giuseppe Modolo

\begin{abstract}
This work focuses on the reprocessability of metallic ${ }^{92} \mathrm{Mo}$ and ceramic $\mathrm{MgO}$, which is under investigation for (Pu,MA)-oxide ( $\mathrm{MA}=$ minor actinide) fuel within a metallic ${ }^{92} \mathrm{Mo}$ matrix (CERMET) and a ceramic $\mathrm{MgO}$ matrix (CERCER). Magnesium oxide and molybdenum reference samples have been fabricated by powder metallurgy. The dissolution of the matrices was studied as a function of $\mathrm{HNO}_{3}$ concentration $(1-7 \mathrm{~mol} / \mathrm{L})$ and temperature $\left(25-90^{\circ} \mathrm{C}\right)$. The rate of dissolution of magnesium oxide and metallic molybdenum increased with temperature. While the $\mathrm{MgO}$ rate was independent of the acid concentration (1-7 mol/L), the rate of dissolution of Mo increased with acid concentration. However, the dissolution of Mo at high temperatures and nitric acid concentrations was accompanied by precipitation of $\mathrm{MoO}_{3}$. The extraction of uranium, americium, and europium in the presence of macro amounts of Mo and $\mathrm{Mg}$ was studied by three different extraction agents: tri- $n$-butylphosphate (TBP), $N, N^{\prime}$-dimethyl- $N, N^{\prime}$-dioctylhexylethoxymalonamide (DMDOHEMA), and $N, N, N^{\prime}, N^{\prime}-$ -tetraoctyldiglycolamide (TODGA). With TBP no extraction of Mo and Mg occurred. Both matrix materials are partly extracted by DMDOHEMA. Magnesium is not extracted by TODGA $(\mathrm{D}<0.1)$, but a weak extraction of Mo is observed at low Mo concentration.
\end{abstract}

Key words: CERCER $\bullet$ CERMET $\bullet$ dissolution $\bullet$ inert matrix fuels (IMF) $\bullet$ liquid-liquid extraction $\bullet$ minor actinides $\bullet$ reprocessing

E. L. Ebert, A. Bukaemskiy, F. Sadowski, S. Lange, A. Wilden, G. Modolo ${ }^{\bowtie}$

Institut für Energie- und Klimaforschung, Nukleare

Entsorgung und Reaktorsicherheit (IEK-6),

Forschungszentrum Jülich GmbH (FZJ),

52425 Jülich, Germany,

Tel.: +49 246161 4896, Fax: +49 246161 2450,

E-mail: g.modolo@fz-juelich.de

Received: 19 June 2015

Accepted: 15 September 2015

\section{Introduction}

During the generation of electricity by nuclear power, considerable amounts of short- and long-lived radioactive fission products as well as considerable quantities of bred plutonium (1 wt\%) and minor actinides (MA) $(0.1 \mathrm{wt} \%)$ are generated. Plutonium and MA (especially americium) are of particular concern with respect to long-term radiotoxicity, heat load issues and proliferation risks. The partitioning and transmutation (P\&T) of MA in accelerator driven systems (ADS) is one possibility to cope with this problem [1-3].

(Pu,MA)-Oxide within a ceramic MgO matrix (CERCER) and (Pu,MA)-oxide within a metallic ${ }^{92}$ Mo matrix (CERMET) were proposed as ADS fuel on the basis of various experiments, such as FUTURIX-FTA, HELIOS, BODEX, and ECRIX-H, on the irradiation performance of inert matrix fuels (IMF) with a matrix content $>60$ vol.\% [4-6]. Mo-based fuels showed safety advantages, while $\mathrm{MgO}$-based inert matrix fuels were superior with regard to transmutation performance [7]. The reprocessability of these IMF is under investigation within the EU project ASGARD [8]. The ADS fuel cycle is capable of recycling a high concentration of minor actinides in the fuel. However, multi cycles are needed as well as specific separation processes for the specific fuel. Enriched ${ }^{92}$ Mo is used because 
of its favorable neutronic parameters and needs to be recovered. The inert matrix material should not give rise to new radioactive waste that needs to be safely disposed of as low or medium active waste [9].

Hydrometallurgical processes using solvent extraction technology are the industry standard for used light water reactor fuel reprocessing with the plutonium uranium reduction extraction (PUREX) process as the basis for all current commercial scale reprocessing plants. It consists of the initial dissolution of fuel into nitric acid and the consecutive separation. The fuel is dissolved in hot concentrated $\mathrm{HNO}_{3}$. This step, which takes a few hours, dissolves the uranium, plutonium, and fission products, leaving the undissolved cladding to be disposed of as high active solid waste. A solution of 30\% tri- $n$ -butylphosphate (TBP) in kerosene type diluent is used initially to separate $\mathrm{U}$ and $\mathrm{Pu}$ from the vast majority of the fission products [10].

In order to achieve a significant reduction in long-term radiotoxicity of the high active waste, Am and $\mathrm{Cm}$ must also be separated from the PUREX raffinate, which is currently vitrified for subsequent disposal in deep geological repositories. The processes that have been developed over the past 20 years, are mainly based on the co-extraction of trivalent actinides and lanthanides and their subsequent separation $[2,11]$. The separation of $A n(I I I)+\operatorname{Ln}($ III) from PUREX raffinate in a process called DIAMEX (diamide extraction) was proposed in the 1980s [12]. $N, N^{\prime}$-dimethyl- $N, N^{\prime}$-dioctylhexylethoxymalonamide (DMDOHEMA) has become the reference molecule for the DIAMEX processs $[13,14]$ enhancing the extractive properties towards trivalent elements and shortening the degradation compounds formed by acidic hydrolysis and radiolysis [15]. Recently, a new process for recovery of trivalent actinides from PUREX-type raffinate utilizing $N, N, N^{\prime}, N^{\prime}-$ -tetraoctyldiglycolamide (TODGA) was developed [16-22]. In a first step a very efficient extraction of $\mathrm{An}$ (III) and $\mathrm{Ln}$ (III) from acidic medium is performed, followed by their stripping using diluted nitric acid [19].

In this paper the reprocessability of magnesia and molybdenum based IMF is under investigation. This includes a brief investigation of their dissolution behavior at different acid concentrations $(1-7 \mathrm{~mol} / \mathrm{L})$ and temperatures (room temperature and $90^{\circ} \mathrm{C}$ ), although the main focus is on extraction. The extractability of $\mathrm{Mg}$ and Mo as well as the influence of macro amounts of matrix material on the extraction of $\mathrm{U}(\mathrm{VI}), \mathrm{Eu}(\mathrm{III})$, and Am(III) were examined. Extraction studies with TBP were performed under PUREX conditions. The two well-known DIAMEX type extractants DMDOHEMA and TODGA were studied for actinide(III) and lanthanide(III) extraction.

\section{Experimental}

\section{Pellet fabrication}

To investigate the reprocessability of molybdenum and magnesia based inert matrix fuels reference samples have been prepared. The pellets were characterized by means of density measurements, scanning electron microscope (SEM) investigation, and X-ray diffraction (XRD).

Magnesium oxide powder (Merck, pro analysis) was calcined at $600^{\circ} \mathrm{C}$ for $2 \mathrm{~h}$ and then milled by hand. The powder $(500 \mathrm{mg})$ was compacted into cylindrical pellets with $10 \mathrm{~mm}$ diameter by cold uniaxial pressing. All $\mathrm{MgO}$ pellets were sintered for $5 \mathrm{~h}$ in air atmosphere at $1600^{\circ} \mathrm{C}$. The density, determined by a geometrical method, of the $\mathrm{MgO}$ pellets used for dissolution experiments was $96 \pm 3 \%$ TD (quotient of the theoretical density in percent).

Molybdenum pellets $(10 \mathrm{~mm}$ diameter $)$ were fabricated by compacting $1 \mathrm{~g}$ Mo powder (Strem Chemicals, 99.9\%) at a pressure of $640 \mathrm{MPa}$ using a cold uniaxial press. The pellets were then sintered at $1600^{\circ} \mathrm{C}$ for $5 \mathrm{~h}$ in argon atmosphere. The density of all pellets was measured by the geometrical method and was $92 \pm 1 \%$ TD.

\section{Dissolution experiments}

The influence of temperature and nitric acid concentration on the dissolution of $\mathrm{MgO}$ and Mo pellets was investigated. Dissolution experiments were conducted in a two-necked round-bottom flask equipped with a Liebig condenser. During dissolution, the liquor was stirred using a magnetic stirring bar. An oil bath was used for temperature control. Nitric acid (Merck, pro analysis) was used for all dissolution experiments. If not stated otherwise $20 \mathrm{~mL}$ of acid were provided in the flask per $1 \mathrm{~g}$ of pellet $(\mathrm{MgO}, \mathrm{Mo})$ for each dissolution experiment, the stirring rate was set to $300 \mathrm{rpm}$, and the temperature was adjusted, then the pellet was added. During the dissolution process $50 \mu \mathrm{L}$ samples were taken and measured in a calibration range of 0.1 to $100 \mu \mathrm{g} / \mathrm{L}$ with appropriate dilution of the analyte in $1 \% \mathrm{v} / \mathrm{v} \mathrm{HNO}_{3}$ (suprapure) solution. Molybdenum samples were centrifuged prior to dilution; for magnesium samples filtration and centrifugation was proven to be unnecessary. The inductively coupled plasma mass spectroscopy (ICP-MS) measurements were realized with the Elan 6100 DRC apparatus, developed by PerkinElmer and SCIEX.

\section{Extraction experiments}

The extraction of Mo, Mg, U, Am, and Eu by three different solvents was tested. The used solvents were:

- 30\% TBP in TPH (hydrogenated tetrapropene, industrial kerosene diluent), PUREX solvent;

- $0.6 \mathrm{~mol} / \mathrm{L}$ DMDOHEMA in Exxsol-d80 (industrial kerosene diluent), DIAMEX solvent;

- $0.2 \mathrm{~mol} / \mathrm{L}$ TODGA in Exxsol-d80 (industrial kerosene diluent), DIAMEX-like solvent.

Equal volumes of $500 \mu \mathrm{L}$ per phase were used in liquid-liquid extraction experiments. Aqueous solutions were spiked with trace amounts of ${ }^{\text {nat }} U$, ${ }^{241} \mathrm{Am}$ and ${ }^{152} \mathrm{Eu}$, respectively. 
Table 1. Magnesium solutions used for solvent extraction studies

\begin{tabular}{lcc}
\hline $\begin{array}{c}\text { Mg concentration } \\
{[\mathrm{g} / \mathrm{L}]}\end{array}$ & $\begin{array}{c}\text { Acidity } \\
{[\mathrm{mol} / \mathrm{L}]}\end{array}$ & $\begin{array}{c}\mathrm{c}\left(\mathrm{NO}_{3}^{-}\right) \\
{[\mathrm{mol} / \mathrm{L}]}\end{array}$ \\
\hline 0.008 & 2.89 & 3.09 \\
0.081 & 2.84 & 3.09 \\
0.784 & 2.67 & 3.09 \\
7.85 & 2.37 & 3.09 \\
23.6 & 1.23 & 3.09 \\
37.5 & 0.01 & 3.09 \\
\hline
\end{tabular}

Magnesium solutions $(0.008-37.5 \mathrm{~g} / \mathrm{L})$ were prepared by dissolving a weighted amount of $\mathrm{MgO}$ in $3.09 \mathrm{~mol} / \mathrm{L} \mathrm{HNO}_{3}$. Accordingly, the acid concentration decreased with increasing $\mathrm{Mg}$ concentration, due to partial neutralization of $\mathrm{HNO}_{3}$ (compare Eq. (1)), while the nitrate concentration was constant. An overview of the Mg concentrations and the corresponding acid and nitrate concentrations of aqueous solutions used for the extraction experiments is shown in Table 1 . The acid concentration of aqueous solutions was determined by potentiometric titration with a '798 MPT Titrino' from Metrohm. Titrations were carried out with 0.01 molar $\mathrm{NaOH}$ solutions.

Increasing weighted amounts of $\left(\mathrm{NH}_{4}\right)_{6} \mathrm{Mo}_{7} \mathrm{O}_{24} \cdot 4 \mathrm{H}_{2} \mathrm{O}$ were dissolved in $3.09 \mathrm{~mol} / \mathrm{L} \mathrm{HNO}_{3}$ for preparation of Mo solutions, keeping the nitrate concentration constant. The acid concentrations were determined by potentiometric titration, as described above, although simple measurement of the $\mathrm{H}^{+}$concentration might not be sufficient to describe the extremely complex acido-basic Mo(VI) chemistry. An overview of the Mo concentrations and the corresponding acid and nitrate concentrations is shown in Table 2.

The batch extraction experiments were performed in $2 \mathrm{~mL}$ glass vials in a thermostatted aluminum block at $22^{\circ} \mathrm{C}$ and the extraction time was $15 \mathrm{~min}$.

The radioisotopes ${ }^{241} \mathrm{Am}$ and ${ }^{152} \mathrm{Eu}$ were directly analyzed using a high-purity germanium spectrometer system (EG\&G Ortec, Munich, Germany; equipped with the Gamma Vision software) without any additional sample preparation. The $\gamma$-lines at $59.5 \mathrm{keV}$ and $121.8 \mathrm{keV}$ were examined for intensities of ${ }^{241} \mathrm{Am}$ and ${ }^{152} \mathrm{Eu}$, respectively. The results are reported as distribution ratios $\mathrm{D}\left(\mathrm{D}=\left[\mathrm{M}_{\mathrm{org}}\right] /\left[\mathrm{M}_{\mathrm{aq}}\right]\right)$, which have an uncertainty of $\pm 5 \%$, detection limits are $500>\mathrm{D}>0.002$.

$\mathrm{Mg}, \mathrm{Mo}$, and U were analyzed using ICP-MS to determine the concentration of each element in the organic and aqueous phase. The aqueous phases

Table 2. Overview of the Mo concentrations and the corresponding acid and nitrate concentrations

\begin{tabular}{lcc}
\hline $\begin{array}{c}\text { Mo concentration } \\
{[\mathrm{g} / \mathrm{L}]}\end{array}$ & $\begin{array}{c}\text { Acidity } \\
{[\mathrm{mol} / \mathrm{L}]}\end{array}$ & $\begin{array}{c}\mathrm{c}\left(\mathrm{NO}_{3}^{-}\right) \\
{[\mathrm{mol} / \mathrm{L}]}\end{array}$ \\
\hline 0.010 & 3.09 & 3.09 \\
0.102 & 3.09 & 3.09 \\
1.02 & 3.08 & 3.09 \\
9.57 & 3.02 & 3.09 \\
43.4 & 2.74 & 3.09 \\
106.2 & 2.23 & 3.09 \\
\hline
\end{tabular}

were diluted with $1 \% \mathrm{HNO}_{3}$ (suprapure) to an appropriate concentration and measured directly. The organic phases were diluted with $1 \% \mathrm{HNO}_{3}$ (suprapure) containing $0.2 \%$ Triton-X 100 in order to disperse the organic phase in the sample homogenously. The results are given as distribution ratios $\mathrm{D}$.

\section{Results and discussion}

\section{Dissolution behavior}

In preparation for the well-established PUREX process spent fuel is dissolved in near boiling 7-10 $\mathrm{mol} / \mathrm{L}$ nitric acid [10, 23]. Therefore, the dissolution behavior of $\mathrm{MgO}$ and Mo based inert matrix fuel was investigated in the heat $\left(90^{\circ} \mathrm{C}\right)$. However, $\mathrm{PuO}_{2}$ is expected to partially dissolve in concentrated nitric acid at elevated temperatures, but potentially less at mild conditions (room temperature, dilute nitric acid). The dissolution of plutonium from fresh and spent $\mathrm{PuO}_{2}$ or MOX is complex and depends on synthesis, microstructure, and thermal as well as irradiation history [24-26]. The aim of this work is to evaluate conditions at which the matrix material can be selectively dissolved without dissolving high amounts of $\mathrm{PuO}_{2}$. Therefore, dissolution behavior at mild conditions is also investigated. If the matrix material could be selectively dissolved and separated in a first dissolution step at mild conditions, the $\mathrm{PuO}_{2}$ would then be dissolved in an additional step utilizing, e.g. boiling concentrated $\mathrm{HNO}_{3}$ and $\mathrm{Ag}(\mathrm{II})$ or $\mathrm{Ce}(\mathrm{IV})$ as catalysts [24-26].

The dissolution of MgO may be described by the following equation [27]:

$$
\mathrm{MgO}+2 \mathrm{H}^{+} \rightarrow \mathrm{Mg}^{2+}+\mathrm{H}_{2} \mathrm{O}
$$

Figure 1 displays the dissolution kinetics of ceramic $\mathrm{MgO}$ pellets at $90^{\circ} \mathrm{C}$ (open symbols) and at room temperature (filled symbols) in initially 2.5 and $7 \mathrm{~mol} / \mathrm{L} \mathrm{HNO}_{3}$. The intermediate acid concentrations were also examined, but are not shown here for reasons of clarity. In the heat $\mathrm{MgO}$ pellets quantitatively dissolved within about one hour. The acid concentration has barely any effect on the rate of dissolution of $\mathrm{MgO}$ in the range of 2.5 to $7 \mathrm{~mol} / \mathrm{L}$, but the rate of dissolution is strongly dependent on the temperature. Complete dissolution of a $\mathrm{MgO}$ pellet in nitric acid at room temperature is achieved within one day. The temperature dependence of dissolution rates is typically expressed using Arrhenius law:

$$
\mathrm{k}=\mathrm{Ae}^{-\mathrm{E} / \mathrm{RT}}
$$

with the pre-exponential factor $\mathrm{A}$, the activation energy $\mathrm{E}$, the rate constant $\mathrm{k}$, the gas constant $\mathrm{R}$ and the temperature $\mathrm{T}$. The activation energies for the different acid concentrations were calculated from the slopes of the linear fits (not shown here). The obtained activation energies for dissolution of magnesia in nitric acid of different concentration show no clear trend but vary in the range from 40 to $60 \mathrm{~kJ} / \mathrm{mol}$, which indicates a surface controlled dissolution [28]. 


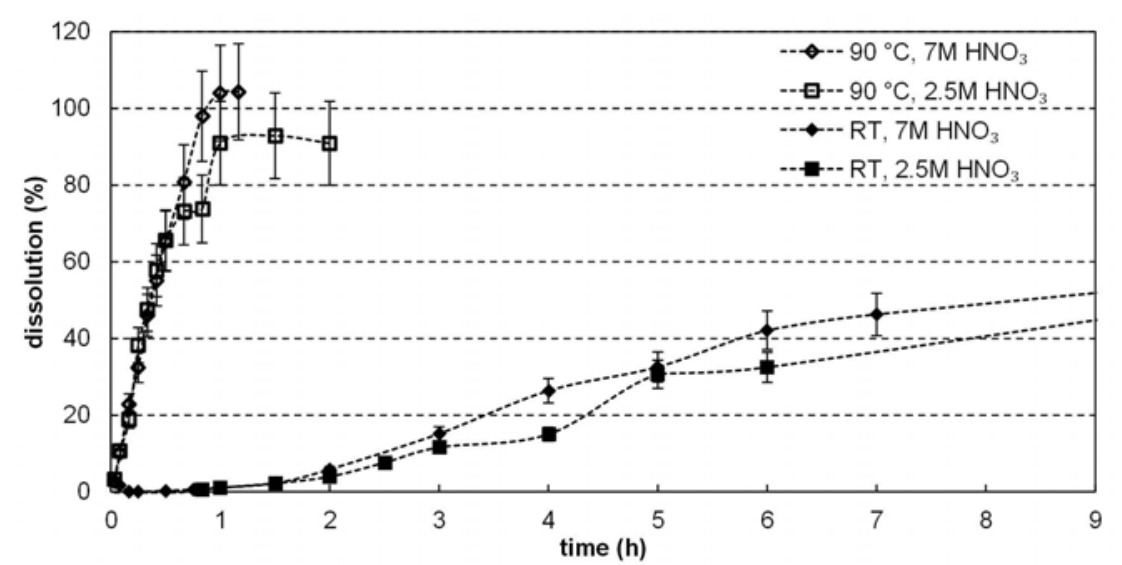

Fig. 1. Dissolution of $\mathrm{MgO}$ pellets in 2.5 and $7 \mathrm{~mol} / \mathrm{L} \mathrm{HNO}_{3}$ at room temperature (filled symbols) and $90^{\circ} \mathrm{C}($ open symbols).

The surface or microstructure plays a key role in dissolution [29, 30] and hence, the dissolution rate is usually normalized to the reactive surface area to allow comparability with other samples with different microstructure or geometry. However, well-established methods such as BET (Brunauer-Emmet-Teller) cannot be applied to pellets. A possibility to get a better evaluation of the pellet surface would be with a method based on SEM observation as described by Horlait et al. [31], but this is beyond the scope of this paper. However, it should be briefly mentioned that several indications were found for a surface controlled dissolution. For instance, we observed a heterogeneous surface development during dissolution, which can probably be attributed to heterogeneous crystal orientations. This is in agreement with the observation by Suárez and Compton [32] within an atomic force microscopy study, that the different surfaces of the MgO crystal (100), (110), and (111) dissolve in hydrochloric acid via heterogeneous etch patterns.

The dissolution of molybdenum is an oxidative process which may be described by the following equation:

$$
\mathrm{Mo}+2 \mathrm{HNO}_{3} \rightarrow \mathrm{MoO}_{3}+2 \mathrm{NO}+\mathrm{H}_{2} \mathrm{O}
$$

However, the produced $\mathrm{MoO}_{3}$ does not readily dissolve in nitric acid [33]. The aqueous chemistry of molybdenum is quite complex. The speciation of molybdenum has been studied intensively in hydrochloric and perchloric acid medium, but little is known about the speciation in nitric acid medium, especially at high acidities, which are relevant for the dissolution of IMF. Molybdenum(VI) is well known to exist as molybdate in alkaline solutions of $\mathrm{pH}>7$. With an increase in the molybdenum concentration molybdate ions polymerize to form isopolymolybdates, which have been reported to exist in the region of molybdenum concentrations $>10^{-4} \mathrm{~mol} / \mathrm{L}$. Below this concentration, acidification of the molybdate proceeds to form monoprotonated, diprotonated and finally cationic species. Cationic species exist in the region of $\mathrm{pH}$ below one. In the acidic region, the existence of dimeric cations has been suggested in the more concentrated solutions of molybdenum [34]. The speciation of molybdenum during dissolution of molybdenum pellets was studied by electrospray ionization mass spectrometry (ESI-MS), but is beyond the scope of this paper and will be published elsewhere.

The typical dissolution kinetics of metallic Mo pellets at $90^{\circ} \mathrm{C}$ (open symbols) and at room temperature (filled symbols) in 1 and $7 \mathrm{~mol} / \mathrm{L} \mathrm{HNO}_{3}$ is depicted in Fig. 2. Unlike $\mathrm{MgO}$, the dissolution behavior of molybdenum in nitric acid strongly depends on the acid concentration; the rate of dissolution velocity in $7 \mathrm{~mol} / \mathrm{L} \mathrm{HNO}_{3}$ was significantly higher than in $1 \mathrm{~mol} / \mathrm{L} \mathrm{HNO}_{3}$. However, during dissolution of a Mo pellet in $7 \mathrm{~mol} / \mathrm{L}$ nitric acid at $90^{\circ} \mathrm{C}$ a huge

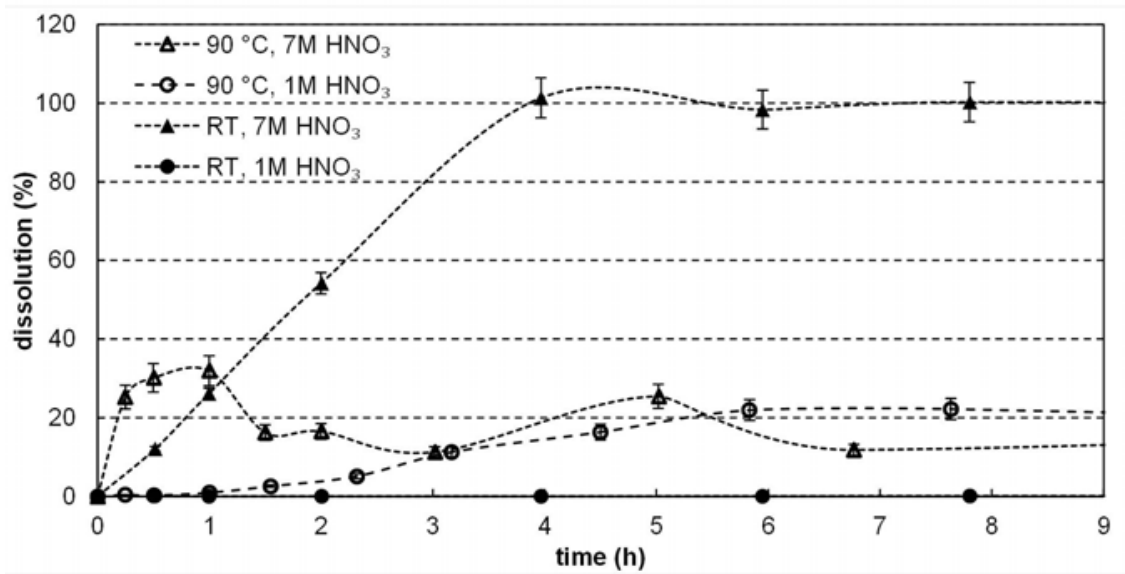

Fig. 2. Dissolution of Mo pellets in 1 and $7 \mathrm{~mol} / \mathrm{L} \mathrm{HNO}_{3}$ at room temperature (filled symbols) and $90^{\circ} \mathrm{C}$ (open symbols). 


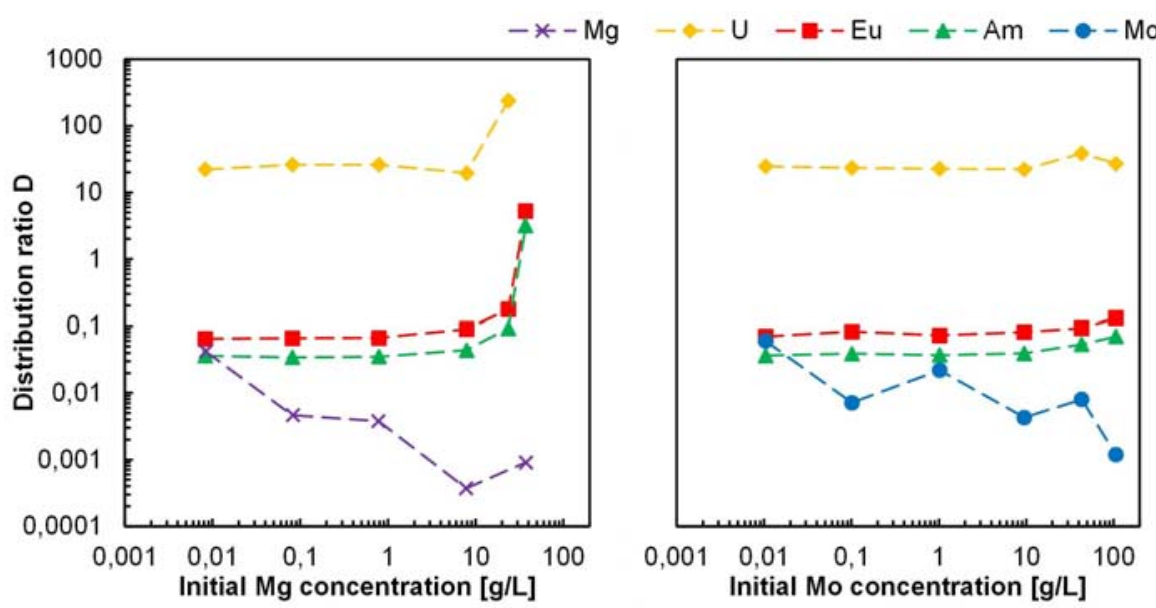

Fig. 3. Distribution ratios of $\mathrm{Mg}(\mathrm{II}), \mathrm{Eu}(\mathrm{III}), \mathrm{Am}(\mathrm{III}), \mathrm{U}(\mathrm{VI})$, and $\mathrm{Mo}(\mathrm{VI})$ using TBP in the organic phase and nitric acid solutions with increasing Mg or Mo concentrations in the aqueous phase. Organic phase: $30 \%$ TBP in TPH, Aqueous phase: (left) increasing amount of $\mathrm{Mg}(8-38 \mathrm{~g} / \mathrm{L})$ in initially $3 \mathrm{~mol} / \mathrm{L} \mathrm{HNO}_{3}$, (right) increasing amount of Mo (10-90 g/L) in initially $3 \mathrm{~mol} / \mathrm{L} \mathrm{HNO}_{3}$.

amount of precipitation occurred within the first 30 min of the dissolution. The molybdenum concentration in the solution increased during the initial phase of the dissolution. However, it then decreased due to the onset of the precipitation and did not exceed $20 \%$ of the expected amount. The dissolution of Mo at room temperature is expected to proceed with significantly less precipitation. Compared to the dissolution at $90^{\circ} \mathrm{C}$, only a very low amount of precipitation occurred instantly at room temperature. Precipitates formed at all investigated conditions and were identified as $\mathrm{MoO}_{3}$ (molybdite) by XRD. $\mathrm{X}$-ray diffraction analyses were performed in the range from 10 to $100^{\circ} 2 \theta$ at room temperature with the D8 Advance ( $\theta-2 \theta$ geometry) and the D4 Endeavor ( $\theta-\theta$ geometry) from Bruker AXS GmbH. All precipitates were hand milled prior to analysis. However, only about $5 \%$ of the molybdenum precipitated in 1 molar nitric acid at room temperature, while about $80 \%$ precipitated in $7 \mathrm{~mol} / \mathrm{L} \mathrm{HNO}_{3}$ in the heat.

Both molybdenum and magnesia can be dissolved at mild conditions although the dissolution is faster at elevated temperatures. However, a quantitative separation will not be achieved during dissolution and needs to be accomplished in a subsequent separation step.

\section{Extraction}

First, the extractability of $\mathrm{Mg}^{2+}$ and $\mathrm{Mo}^{6+}$ was investigated by the PUREX solvent 30\% TBP in TPH. Additionally, the influence of increasing $\mathrm{Mg}$ and $\mathrm{Mo}$ concentration on uranium, americium and europium extraction was studied. For this purpose the solutions were spiked with trace amounts of nat ${ }^{241} \mathrm{Am}$ and ${ }^{152} \mathrm{Eu}$, although $\mathrm{Mo}(\mathrm{VI})$ is a proven complexing agent for U(VI) [35].

With the PUREX solvent Mg was not extracted $(\mathrm{D}<0.1)$. Uranium was well extracted with distribution ratios of $\sim 25$ (Fig. 3, left). Americium and europium were poorly extracted with $\mathrm{D}<0.1$, although at the highest initial Mg concentration an increase in the $\mathrm{Am} / \mathrm{Eu}$ distribution ratios was observed. This was caused by the decreasing acid concentration as shown in Table 1 for the Mg system and Table 2 for the Mo system, while the nitrate concentration was constant. It is well known that TBP extracts also nitric acid at high acidity by solvation mechanism. Thus at low acitity the free TBP concentration in the organic phase is higher, resulting in increased uranium, americium and europium distribution ratios. Molybdenum was also not extracted $(\mathrm{D}<$ $0.1)$. Uranium was well extracted in the presence of molybdenum with distribution ratios of $\sim 22$ (Fig. 3, right). Americium and europium were poorly extracted with $\mathrm{D}$ ratios $\sim 0.1$. No third phase formation nor precipitation was observed in both cases.

Magnesium as well as molybdenum were not extracted by the PUREX solvent 30\% TBP in TPH, but remained in the aqueous phase together with the lanthanides and minor actinides. Therefore, the extractability of $\mathrm{MgO}$ and Mo by DIAMEX type solvents as well as their influence on the extraction of actinides and lanthanides is explored in the next step.

With the DIAMEX solvent, a fine precipitation was observed at $\mathrm{c}_{\text {ini }}(\mathrm{Mg})=38 \mathrm{~g} / \mathrm{L}$. Magnesium was not extracted with $\mathrm{D} \sim 0.01$ at the lower initial $\mathrm{Mg}$ concentrations. However, an increasing extraction of $\mathrm{Mg}$ was observed at the highest initial Mg concentrations. The increasing extraction of $\mathrm{Mg}$ with DMDOHEMA was surprising and needs to be further investigated. However, the behavior of the actinides (U, Am) and Eu is in line with literature data. Uranium was very well extracted (D 100), and Am $(\mathrm{D} \sim 5)$ and $\mathrm{Eu}(\mathrm{D} \sim 3)$ were well extracted (Fig. 4, left). Third phase formation was also observed in the Mo system at $\mathrm{c}_{\text {ini }}(\mathrm{Mo})=43 \mathrm{~g} / \mathrm{L}$ and a precipitation occurred at $c_{\text {ini }}(\mathrm{Mo})=90 \mathrm{~g} / \mathrm{L}$. This was due to the good extraction of Mo by DMDOHEMA, with D reaching a maximum of 4 (Fig. 4, right). Uranium was very well extracted $(\mathrm{D}>100)$, and Am (D $4)$ and $\mathrm{Eu}(\mathrm{D} \sim 2)$ were well extracted.

In the presence of macro amounts $\mathrm{Mg}$, no third phase formation or precipitation was observed with TODGA. Magnesium was not extracted, with D $\sim 0.01$. Uranium was well extracted with $\mathrm{D} \sim 10$ and $\mathrm{Am}$ and Eu were very well extracted with D 

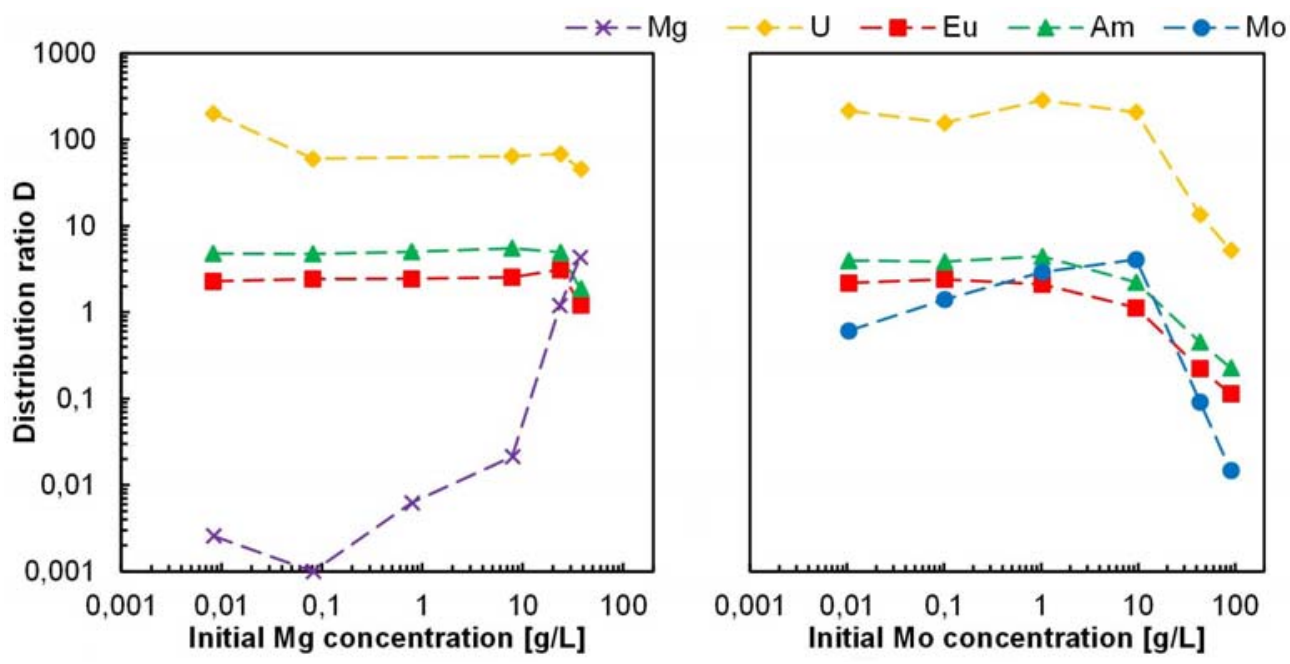

Fig. 4. Distribution ratios of $\mathrm{Mg}(\mathrm{II}), \mathrm{Eu}(\mathrm{III}), \mathrm{Am}(\mathrm{III}), \mathrm{U}(\mathrm{VI})$, and Mo(VI) using DMDOHEMA in the organic phase and nitric acid solutions with increasing $\mathrm{Mg}$ or Mo concentrations in the aqueous phase. Organic phase: $0.6 \mathrm{~mol} / \mathrm{L}$ DMDOHEMA in Exxsol-d80. Aqueous phase: (left) increasing amount of $\mathrm{Mg}(8-38 \mathrm{~g} / \mathrm{L})$ in initially $3 \mathrm{~mol} / \mathrm{L} \mathrm{HNO}_{3}$, (right) increasing amount of $\mathrm{Mo}(10-90 \mathrm{~g} / \mathrm{L})$ in initially $3 \mathrm{~mol} / \mathrm{L}^{\mathrm{HNO}_{3}}$.

$>100$ (Fig. 5, left). In the case of molybdenum a fine precipitate was observed at $\mathrm{c}_{\mathrm{ini}}(\mathrm{Mo})=90 \mathrm{~g} / \mathrm{L}$. Molybdenum was moderately extracted with $\mathrm{D}$ of 2.5 at low initial Mo concentration, while decreasing Mo distribution ratios are observed at higher Mo concentrations (Fig. 5, right). Uranium was well extracted with $\mathrm{D} \sim 10$ and Am and Eu were very well extracted with $\mathrm{D}>100$.

The extraction results show that Mo is partly extracted by DMDOHEMA and TODGA, causing third phase formation or precipitation problems at the highest initial Mo-concentrations. The behavior of the actinides (U, Am) and $\mathrm{Eu}$ is in line with literature data [36-39].

\section{Conclusions and outlook}

The dissolution of $\mathrm{MgO}$ is possible even under relatively mild conditions $\left(2.5 \mathrm{~mol} / \mathrm{L} \mathrm{HNO}_{3}\right.$, room temperature). Magnesium oxide could be separated in a first dissolution step at mild conditions, while the actinides would be dissolved in an additional step utilizing, e.g. boiling concentrated $\mathrm{HNO}_{3}$.

The rate of dissolution of Mo was strongly dependent on the acid concentration as well as the temperature. The dissolution of Mo pellets in $\mathrm{HNO}_{3}$ was complex. It was accompanied by precipitation, especially at high acid concentrations and temperatures. Further dissolution optimization studies are planned in the near future in glove boxes (fresh $\mathrm{PuO}_{2}$ + Mo matrix pellets).

The matrix elements Mg and Mo were not extracted using the PUREX solvent. In the DIAMEX solvent Mg was extracted at low acidity, while Mo was extracted with moderate distribution ratios. The TODGA solvent was not able to extract Mg, but Mo was slightly extracted at low Mo concentrations. However, both the DMDOHEMA and the TODGA system suffer from third phase formation and pre-
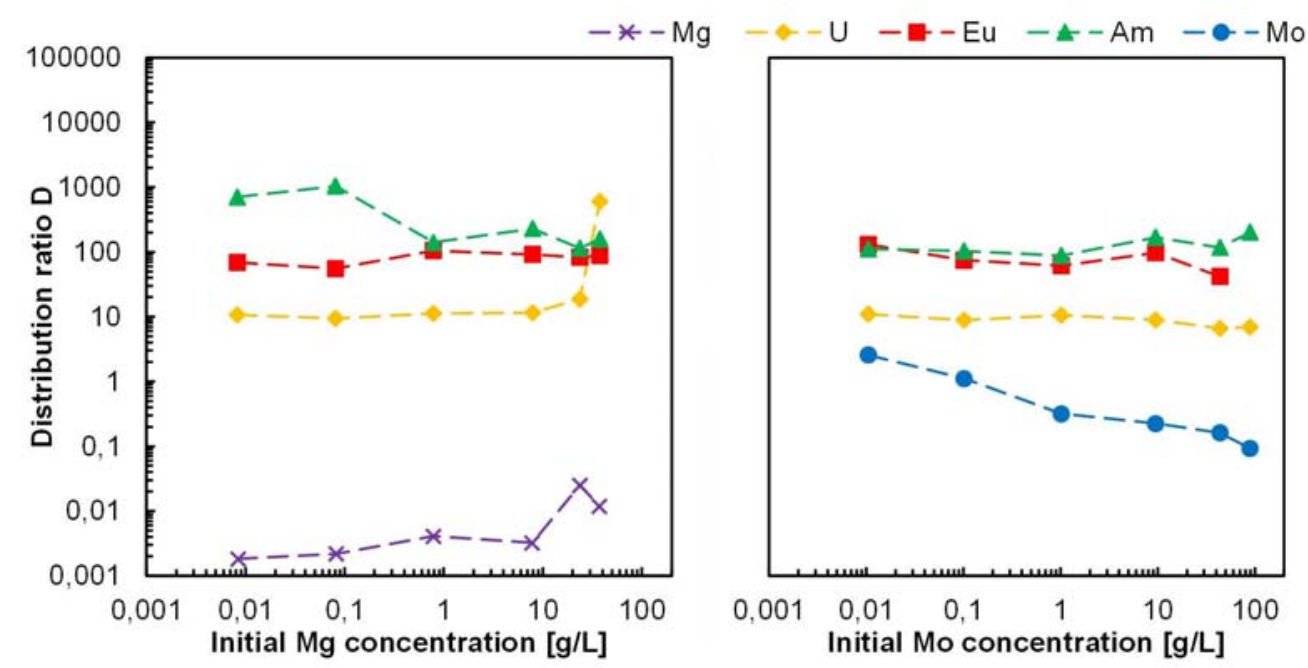

Fig. 5. Distribution ratios of $\mathrm{Mg}(\mathrm{II}), \mathrm{Eu}(\mathrm{III}), \mathrm{Am}(\mathrm{III}), \mathrm{U}(\mathrm{VI})$, and $\mathrm{Mo}(\mathrm{VI})$ using TODGA in the organic phase and nitric acid solutions with increasing Mg or Mo concentrations in the aqueous phase. Organic phase: 0.2 mol/L TODGA in Exxsol-d80. Aqueous phase: (left) increasing amount of $\mathrm{Mg}(8-38 \mathrm{~g} / \mathrm{L})$ in initially $3 \mathrm{~mol} / \mathrm{L} \mathrm{HNO}_{3}$, (right) increasing amount of Mo (10-90 g/L) in initially $3 \mathrm{~mol} / \mathrm{L} \mathrm{HNO}_{3}$. 
cipitation issues, which will have to be resolved. However, methods have to be developed to separate $\mathrm{Mg}$ and Mo to improve the final conditioning of the remaining fission products before vitrification.

Acknowledgments. Financial support for this research was provided by the European Atomic Energy Community's 7th Framework Programme (FP7 2007-2011), project ASGARD - grant agreement no. 295825.

\section{References}

1. Pillon, S. (2012). Actinide-bearing fuels and transmutation targets. In R. J. M. Konings (Ed.), Comprehensive nuclear materials (Vol. 3, pp. 109-141). Oxford: Elsevier

2. Modolo, G., Wilden, A., Geist, A., Magnusson, D., \& Malmbeck, R. (2012). A review of the demonstration of innovative solvent extraction processes for the recovery of trivalent minor actinides from PUREX raffinate. Radiochim. Acta, 100, 715-725. DOI: 10.1524/ract.2012.1962.

3. Montel, J. -M. (2011). Minerals and design of new waste forms for conditioning nuclear waste. C. R. Geosci., 343, 230-236. DOI: 10.1016/j. crte.2010.11.006.

4. Lamontagne, J., Béjaoui, S., Hanifi, K., Valot, C., \& Loubet, L. (2011). Swelling under irradiation of MgO pellets containing americium oxide: The ECRIX-H irradiation experiment. J. Nucl. Mater., 413, 137-144. DOI: 10.1016/j.jnucmat.2011.04.013.

5. D'Agata, E., Klaassen, F., Sciolla, C., Fernandes-Carretero, A., \& Bonnerot, J. M. (2009). Helios: The new design of the irradiation of U-free fuels for americium transmutation. In Proceedings of the Global, 6-11 September 2009 (pp. 2006-2015). Paris, France.

6. Delage, F., Belin, R., Chen, X. -N., D'Agata, E., Klaassen, F., Knol, S., Maschek, W., Ottaviani, J. P., Rineiski, A., Sobolev, V., Somers, J., Staicu, D., Thetford, R., Wallenius, J., \& Wernli, B. (2010). Minor actinide transmutation in an accelerator-driven system prototype: Results from fuel developments within the European programme EUROTRANS. In Proceedings of the Actinide and Fission Product Partitioning and Transmutation - Eleventh Information Exchange Meeting, 1-4 November 2010 (pp. 177-186). San Francisco.

7. Haas, D., Fernandez, A., Staicu, D., Somers, J., Maschek, W., Liu, P., \& Chen, X. (2008). CERMET fuel behavior and properties in ADS reactors. Energy Conv. Manag., 49, 1928-1933. DOI: 10.1016/j.enconman.2007.12.027.

8. Ekberg, C., deVisser-Tynova, E., Retegan, T., Sarsfield, M., \& Wallenius, J. (2014). ASGARD. In Proceedings of the Sustainable Nuclear Energy Conference SNEC, 9-11 April 2014. Manchester

9. Ouvrier, N., \& Boussier, H. (2012). Recycling of MgO, $\mathrm{Mo} \& \mathrm{ZrO}_{2}$ based actinide-bearing matrices: Assessment of reprocessing feasibility \& waste production. Procedia Chem., 7, 322-327. DOI: 10.1016/j. proche.2012.10.051.

10. Loveland, W. D., Morrissey, D. J., \& Seaborg, G. T. (2006). Modern nuclear chemistry. New York, NY: Wiley.

11. Taylor, R., Bourg, S., Glatz, J. -P., Modolo, G. (2015). Developement of actinide separation processes for future nuclear fuel cycles in Europe. Nucl. Future, 11(4), 38-43.
12. Courson, O., Lebrun, M., Malmbeck, R., Pagliosa, G., Romer, K., Satmark, B., \& Glatz, J. -P. (2000). Partitioning of minor actinides from HLLW using the DIAMEX process. Part 1 - Demonstration of extraction performances and hydraulic behaviour of the solvent in a continuous process. Radiochim. Acta, 88, 857-863. DOI: 10.1524/ract.2000.88.12.857.

13. Serrano-Purroy, D., Christiansen, B., Glatz, J. -P. Malmbeck, R., \& Modolo, G. (2005). Towards a DIAMEX process using high active concentrate. Production of genuine solutions. Radiochim. Acta, 93, 357-361. DOI: 10.1524/ract.93.6.357.65645.

14. Serrano-Purroy, D., Baron, P., Christiansen, B., Malmbeck, R., Sorel, C., \& Glatz, J. -P. (2005). Recovery of minor actinides from HLLW using the DIAMEX process. Radiochim. Acta , 93, 351-355. DOI: 10.1524/ ract.93.6.351.65642.

15. Baron, P., Hérès, X., Lecomte, M., \& Masson, M. (2001). Separation of the minor actinides: the DIAMEX-SANEX concept. In Proceedings of the International Conference on Future Nuclear Systems, GLOBAL'01, 9-13 September 2001. Paris, France.

16. Sasaki, Y., \& Choppin, G. R. (1996). Solvent extraction of $\mathrm{Eu}, \mathrm{Th}, \mathrm{U}, \mathrm{Np}$ and Am with N,N'-dimethyl$\mathrm{N}, \mathrm{N}$ '-dihexyl-3-oxapentanediamide and its analogous compounds. Anal. Sci., 12, 225-230. DOI: 10.2116/ analsci.12.225.

17. Sasaki, Y., \& Choppin, G. R. (1998). Extraction of $\mathrm{Np}(\mathrm{V})$ by N,N'-dimethyl-N,N'-dihexyl-3-oxapentane-diamide. Radiochim. Acta, 80, 85-88. DOI: 10.1524/ ract.1998.80.2.85

18. Sasaki, Y., Sugo, Y., Suzuki, S., \& Tachimori, S. (2001). The novel extractants, diglycolamides, for the extraction of lanthanides and actinides in $\mathrm{HNO}_{3}-n$ dodecane system. Solvent Extr. Ion Exch., 19, 91-103. DOI: $10.1081 /$ sei-100001376.

19. Modolo, G., Vijgen, H., Schreinemachers, C., Baron, P., \& Dinh, B. (2003). TODGA process developement for partitioning of actinides(III) from PUREX raffinate. In Proceedings of the GLOBAL, 16-20 November 2003 (pp. 1926-1930). New Orleans, Louisiana, USA.

20. Geist, A., \& Modolo, G. (2009). TODGA process development: an improved solvent formulation. In Proceedings of the GLOBAL (The Nuclear Fuel Cycle: Sustainable Options \& Industrial Perspectives), 6-11 September 2009 (pp. 1022-1026, paper 9193). Paris, France.

21. Modolo, G., Asp, H., Schreinemachers, C., \& Vijgen, H. (2007). Development of a TODGA based process for partitioning of actinides from a PUREX raffinate Part I: Batch extraction optimization studies and stability tests. Solvent Extr. Ion Exch., 25, 703-721. DOI: 10.1080/07366290701634578.

22. Magnusson, D., Christiansen, B., Glatz, J. P., Malmbeck, R., Modolo, G., Serrano-Purroy, D., \& Sorel, C. (2009). Demonstration of a TODGA based extraction process for the partitioning of minor actinides from a PUREX raffinate. Solvent Extr. Ion Exch., 27, 26-35, DOI: $10.1080 / 07366290802544726$.

23. Fukasawa, T., \& Ozawa, Y. (1986). Relationship between dissolution rate of uranium dioxide pellets in nitric acid solutions and their porosity. J. Radioanal. Nucl. Chem. Lett., 106, 345-356. DOI: 10.1007/ BF02163667.

24. Ryan, J. L., Bray, L. A., Wheelwright, E. J., \& Bryan, G. H. (1990). Catalyzed electrolytic plutonium oxide dissolution (CEPOD): The past seventeen years and future potential. United States: American Chemical Society. 
25. Uriarte, A. L., \& Rainey, R. H. (1965). Dissolution of high-density $\mathrm{UO}_{2}, \mathrm{PuO}_{2}$, and $\mathrm{UO}_{2}-\mathrm{PuO} \mathrm{O}_{2}$ pellets in inorganic acids. Commission, U.S.A.E., Oak Ridge, Tennessee: Oak Ridge National Laboratory. (ORNL3695).

26. Inoue, A. (1988). Enhanced dissolution of $\mathrm{PuO}_{2}$ in nitric acid using uranium(IV). J. Chem. Soc. Faraday Trans., 84, 1195-1197. DOI: 10.1039/F19888401195.

27. Fedorockova, A., \& Raschman, P. (2008). Effects of $\mathrm{pH}$ and acid anions on the dissolution kinetics of MgO. Chem. Eng. J., 143, 265-272. DOI: 10.1016/j. cej.2008.04.029.

28. Jordan, G., \& Rammensee, W. (1996). Dissolution rates and activation energy for dissolution of brucite (001): A new method based on the microtopography of crystal surfaces. Geochim. Cosmochim. Acta, 60, 5055-5062. DOI: 10.1016/S0016-7037(96)00309-2.

29. Lüttge, A., Arvidson, R. S., \& Fischer, C. (2013). A stochastic treatment of crystal dissolution kinetics. Elements, 9, 183-188. DOI: 10.2113/gselements.9.3.183.

30. Finkeldei, S., Brandt, F., Rozov, K., Bukaemskiy, A. A., Neumeier, S., \& Bosbach, D. (2014). Dissolution of $\mathrm{ZrO}_{2}$ based pyrochlores in the acid $\mathrm{pH}$ range: A macroscopic and electron microscopy study. Appl. Geochem., 49, 31-41. DOI: 10.1016/j.apgeochem.2014.06.014

31. Horlait, D., Claparede, L., Tocino, F., Clavier, N., Ravaux, J., Szenknect, S., Podor, R., \& Dacheux, N. (2014). Environmental SEM monitoring of $\mathrm{Ce}_{1-\mathrm{x}} \mathrm{Ln}_{\mathrm{x}} \mathrm{O}_{2-\mathrm{x} / 2}$ mixed-oxide microstructural evolution during dissolution. J. Mater. Chem., 2, 5193-5203, DOI: 10.1039/C3TA14623E.

32. Suárez, M. F., \& Compton, R. G. (1998). Dissolution of magnesium oxide in aqueous acid: An atomic force microscopy study. J. Phys. Chem. B, 102, 7156-7162. DOI: $10.1021 /$ jp982260x.

33. Tytko, K. H. (1989). Mo: Molybdenum. System number 53. Molybdenum oxide hydrates, oxomolybdenum species in aqueous solutions. Berlin: Springer.

34. Fujii, T., Yamana, H., Watanabe, M., \& Moriyama, H. (2001). Extraction of molybdenum from nitric acid by octyl(phenyl)-N,N-diisobutylcarbamoylmethylphosphine oxide. Solvent Extr. Ion Exch., 19, 127-141. DOI: $10.1081 /$ sei-100001378.

35. Saito, A., \& Choppin, G. R. (1998). Complexation of uranyl(VI) with polyoxometalates in aqueous solutions. J. Alloys Compd., 271/273, 751-755. DOI: 10.1016/S0925-8388(98)00200-X.

36. Suzuki, H., Sasaki, Y., Sugo, Y., Apichaibukol, A. \& Kimura, T. (2004). Extraction and separation of Am(III) and Sr(II) by N,N,N',N'-tetraoctyl-3-oxapentanediamide (TODGA). Radiochim. Acta, 92, 463-466. DOI: 10.1524/ract.92.8.463.39276.

37. Ansari, S. A., Pathak, P. N., Manchanda, V. K. Husain, M., Prasad, A. K., \& Parmar, V. S. (2005). $\mathrm{N}, \mathrm{N}, \mathrm{N}^{\prime}, \mathrm{N}^{\prime}$-Tetraoctyl diglycolamide (TODGA): a promising extractant for actinide partitioning from high-level waste (HLW). Solvent Extr. Ion Exch., 23, 463-479. DOI: 10.1081/sei-200066296.

38. Cuillerdier, C., Musikas, C., Hoel, P., Nigond, L., \& Vitart, X. (1991). Malonamides as new extractants for nuclear waste solutions. Separ. Sci. Technol., 26, 1229-1244. DOI: 10.1080/01496399108050526.

39. Cuillerdier, C., Musikas, C., \& Nigond, L. (1993). Diamides as actinide extractants for various waste treatments. Separ. Sci. Technol., 28, 155-175. DOI: 10.1080/01496399308019484. 